\title{
Gender Gap in Political Science: An Analysis of the Scientific Publications and Career Paths of Italian Political Scientists
}

Marco Cellini, Institute for Research on Population and Social Policies of the Italian National Research Council, Italy

ABSTRACT This article assesses whether a gender gap in political science, identified in the international literature, also is present in the context of Italian political science. The literature has mostly centered on the comparison of female publication rates in international journals with the academic workforce in the United States, but this raises an issue of data comparability. As an alternative strategy to avoid comparability biases, this study focuses on the analysis of a single national case: Italy. The article evaluates to what extent the "glass-ceiling" effect persists for political scientists who intend to publish their contributions. By analyzing data on articles published between 2015 and 2020 by the three major Italian political science journals, this contribution shows that (1) the proportion of published articles written by female authors is lower than that of male authors; (2) the hypothesis that the lower female proportion depends on a lower female presence in the field of political science is refuted; (3) there is little collaboration between men and women; (4) there is a correlation between the presence of female editors in scientific journals and the proportion of female-authored articles; and (5) gender differences are reflected in women's academic career progression.

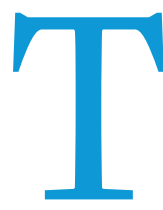

he literature has identified several dimensions within the academic profession where substantial gender gaps exist (Dion, Sumner, and Mitchell, 2018). Differences are present in the evaluation of teaching activities (MacNell, Driscoll, and Hunt 2015), in peer-review processes (Wennerås and Wold 1997), in citation patterns (Dion, Sumner, and Mitchell 2018), and in other related contexts.

The literature highlights a more marked presence of gender differences in the so-called hard-sciences sector; however, it also

Marco Cellini (iD) is a post-doc research fellow at the Institute for Research on Population and Social Policies of the Italian National Research Council. He can be reached at marco.cellini@irpps.cnr.it. points out how the social sciences are still far from achieving gender equality (Avveduto 2019; Wang and Degol 2017). Within the social sciences, research conducted in the specific field of political science has shown that it includes all of these gaps (Alter et al. 2020; Stegmaier, Palmer, and Van Assendelft 2011).

In the United States, the American Political Science Association (APSA $)^{1}$ recognized the presence of a gender-inequality issue in academia. It has embarked on a project to track the career advancement of women to understand at what career level the greatest discrepancies in female researchers occur, and it has found widening gender gaps in the advancement from one level to another.

Among the gender differences found, that of publications in scientific journals is certainly one of the most concerning. The reasons for these differences remain an open question-and 
despite the fact that research on this subject dates to the late 196os, the literature has not reached a commonly accepted conclusion. Throughout the decades, several theories have been proposed to explain the different degree of productivity between female and male researchers, highlighting biological factors (Ceci and Williams 2010), sociological factors (Ceci and Williams 2011), and clear discriminatory intentions (Aguinis, Ji, and Joo 2018).

Nonetheless, the existence of a gender gap represents a problem that must be better understood and addressed. Publishing in scientific journals is an essential part of researchers' work. It is necessary not only for presenting research results to their scientific community; it also is essential for advancement in their career. The expression "publish or perish," which first appeared in 1927 in the American Journal of Sociology and Social Research (Case 1927), perfectly summarizes the need and urgency of researchers to publish their results in appropriate scientific journals.

Young (1995) analyzed publication trends in a sample of 15 international political science journals from 1983 to 1994 . Although in the context of a positive trend, she highlighted how the number of female-authored articles published remained substantially lower than male-authored articles; likewise, the number of articles published by two or more women remained lower than those published by two or more men. Teele and Thelen (2017) analyzed publication trends 20 years later in a sample of 10 international political science journals from 2000 to 2015 and found similar results. Both studies show how this discrepancy has occurred despite a significant increase in the number of women relating to international journal publications are compared primarily to those of the academic profession in the United States. However, there is a problem of data comparability in the analysis of international journals with data relative to the number of academics in a specific country. Because they are prestigious and globally renowned, these journals attract the work of researchers from all over the world, which makes it difficult-and probably biased-to compare the proportion of female publications with that of female researchers and university professors in a specific country.

To overcome this issue, other scholars compared the proportion of female publications with that of women's membership in high-ranked academic association conferences (e.g., the APSA and International Studies Association annual conferences) (Breuning and Sanders 2007; Teele and Thelen 2017). Indeed, this strategy only partially avoids the bias because these conferences, as well as high-ranked international academic journals, attract academics from all over the world.

As an alternative strategy to avoid comparability biases, this study focuses on the analysis of a single national case: Italy. This way, if the results of an analysis do not allow for complete generalization, they would not be subjected to data-comparability issues. It is more likely that only Italy-based scholars are submitting to Italian journals and, therefore, have a closer connection between publications and career progression. However, because the Italian system of attributing value to publications has several similarities to more formal systems adopted outside of the United

\section{As an alternative strategy to avoid comparability biases, this study focuses on the analysis of a single national case: Italy. This way, if the results of an analysis do not allow for complete generalization, they would not be subjected to data-comparability issues.}

entering academic careers that has reduced the participation gap between the two genders.

Following these two studies and in an attempt to explain the gender differences, recent literature has focused primarily on American political science publications. Although these studies have not found gender gaps in journal review processes, they have revealed that submissions are distorted by gender (Breuning et al. 2018; Djupe, Smith, and Sokhey 2019; Nedal and Nexon 2018; Samuels 2018). Brown et al. (2020) showed how this submission bias is influenced by the different perceptions that women and men have concerning the probability of being published by some journals rather than others. Other studies have shown how collaboration patterns also increase the gap; that is, top journals are more likely to send out multi-authored articles for review, but women seem to participate less than men in collaboration networks (Brown and Samuels 2018; Samuels 2018).

The literature on the subject, however, focuses almost exclusively on the analysis of trends in women's publications in international journals, but this presents at least one methodological concern. An often-implicit assumption is that by reducing the gender gap in access to an academic career, there also should be a reduction in the gap in scientific publication rates.

For this reason, most research compares the proportion of articles published by women with that of women with a $\mathrm{PhD}$ and in the role of university professor. Nevertheless, numbers
States, the results in this article may be partially generalizable to other national contexts-or at least compared with future research in similar academic contexts.

Therefore, the purpose of the analysis of career and publication data is to assess whether the gender gap in political science identified in the international scientific literature is confirmed in the context of Italian political science by evaluating if and to what extent the "glass-ceiling" effect persists for female Italian political scientists. The analysis shows that (1) the proportion of published articles written by female authors is lower than that of male authors; (2) the hypothesis that the lower female proportion depends on a lower female presence in the field of political science is refuted; (3) there is little collaboration between men and women; (4) there is a correlation between the presence of female editors in scientific journals and the proportion of female-authored articles; and (5) gender differences are reflected in women's academic career progression.

This article discusses the Italian academic context; describes the data and analysis techniques used; reports the results of the analysis; and presents the conclusions of the research.

\section{THE ITALIAN CONTEXT}

As elsewhere in the world, academic careers in Italy are strongly linked to publications in scientific journals. At the end of their $\mathrm{PhD}$ studies, which are essential for an academic career, scholars' 
scientific publications are evaluated for research-grant competitions. As scholars progress in their academic career, publications are essential to qualify for a position as a researcher with a type A fixed-term contract (RTDa) ${ }^{2}$ and then with a type B fixed-term contract (RTDb). ${ }^{3}$ Ultimately, to become an associate professor (PA) and full professor (PO), their publications are evaluated (in terms of both quantity and quality) in the context of the National Scientific Qualification (ASN), which is necessary to apply for these professional positions.

In Italy, the academic system is divided into research areas, which then are subdivided into competition sectors. The National Agency for the Evaluation of the University and Research System (ANVUR) is responsible for classifying scientific journals (for each area and competition sector), producing lists of those journals considered to be scientific and those considered to be in category A (i.e., the best in terms of the quality of the research published). For career progression, therefore, it is important to publish not only in scientific journals but also in those journals considered the most prestigious and classified by ANVUR as category A.

\section{DATA SELECTION AND ANALYSIS}

This research focuses on the three major Italian political science journals: Rivista Italiana di Scienza Politica (RISP), Filosofia Politica (FS), and Politica $\mathcal{E}$ Società (PES). All three journals are classified by ANVUR as category A for area 14 (i.e., political science and social sciences); RISP for competitive sector A2 (i.e., political

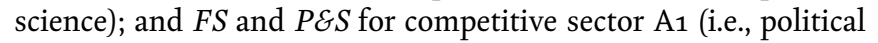
philosophy). Data concerning the articles published refer to the period 2015-2020 (Cellini 2021).

Data were collected using the metadata for each journal from 2015 to 2020 using the Web of Science (WoS) database. This process allowed information to be aggregated for 414 publications by 504 authors. Because the authors' gender was not attributed in the metadata extracted from $\mathrm{WoS}$, it was determined by manually coding the 504 authors (i.e., 139 women and 365 men).

Data related to doctorates and research and teaching staff were collected from the database of the Italian Ministry of Education
University and Research (MIUR). ${ }^{4}$ The data refer to the period 20152019 because the 2020 data were not yet available as of this writing.

Finally, ASN data were collected from the ANVUR ${ }^{5}$ website and refer to the two-year period 2016-2018 (i.e., 2018 was the last year that the ASN occurred).

Regarding the bibliometric analysis, the literature identifies at least three distinct methodologies for the analysis of scientific production: (1) first-author counting, (2) full counting, and (3) fractionalized counting (Egghe and Rousseau 1990; Korytkowski and Kulczycki 2019; Larsen 2008; Van Hooydonk 1997).

For an accurate attribution of publication credits and for a better comparison between years and between journals, the fractionalized-counting method was used in this study. Attributing an equal fraction of the credit to each author normalizes the number of publications relative to the number of authors of a single article, thereby providing a better comparison in terms of gender differences. The publication-credit calculation is described in more detail in the online appendix.

\section{RESULTS}

For the scientific journals and the timeframe analyzed, the total number of articles varied from 113 for $P \mathcal{E} S$ to 176 for FP. For all three journals, the percentage of female authors was significantly lower than that of male authors, ranging from $24 \%$ for FP to $31.3 \%$ for RISP (figure 1).

Although it was relatively higher for two of the three journals, the percentage of female editors also was less than $50 \%$, ranging

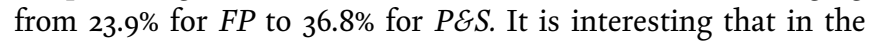
period considered, there is a correlation with a coefficient of 0.744 at a significance level of 0.05 between the percentages of women included on journal editorial boards and female authors. Unfortunately, data on the time trend of female editors are not available; therefore, the results are valid only for the relationship between the actual percentage of female editors and the aggregate percentage of female authors in the journals and years considered.

Review of the overall trend by gender shown in figure 2 indicates that the difference between women and men authors from 2015 to 2020 exhibited a fluctuating trend: the gender gap was progressively

\section{Figure 1}

Authors' Percentage by Gender, 2015-2020

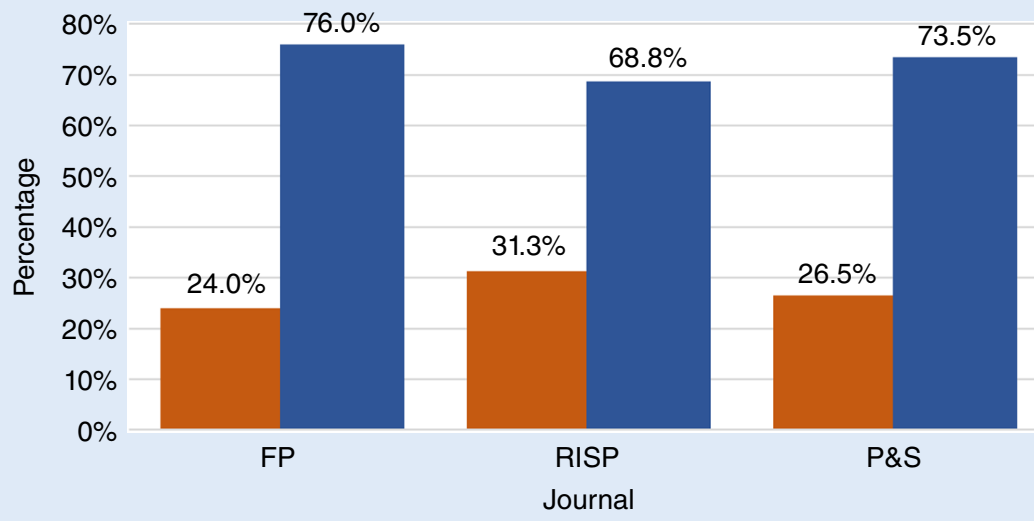

Women Men 


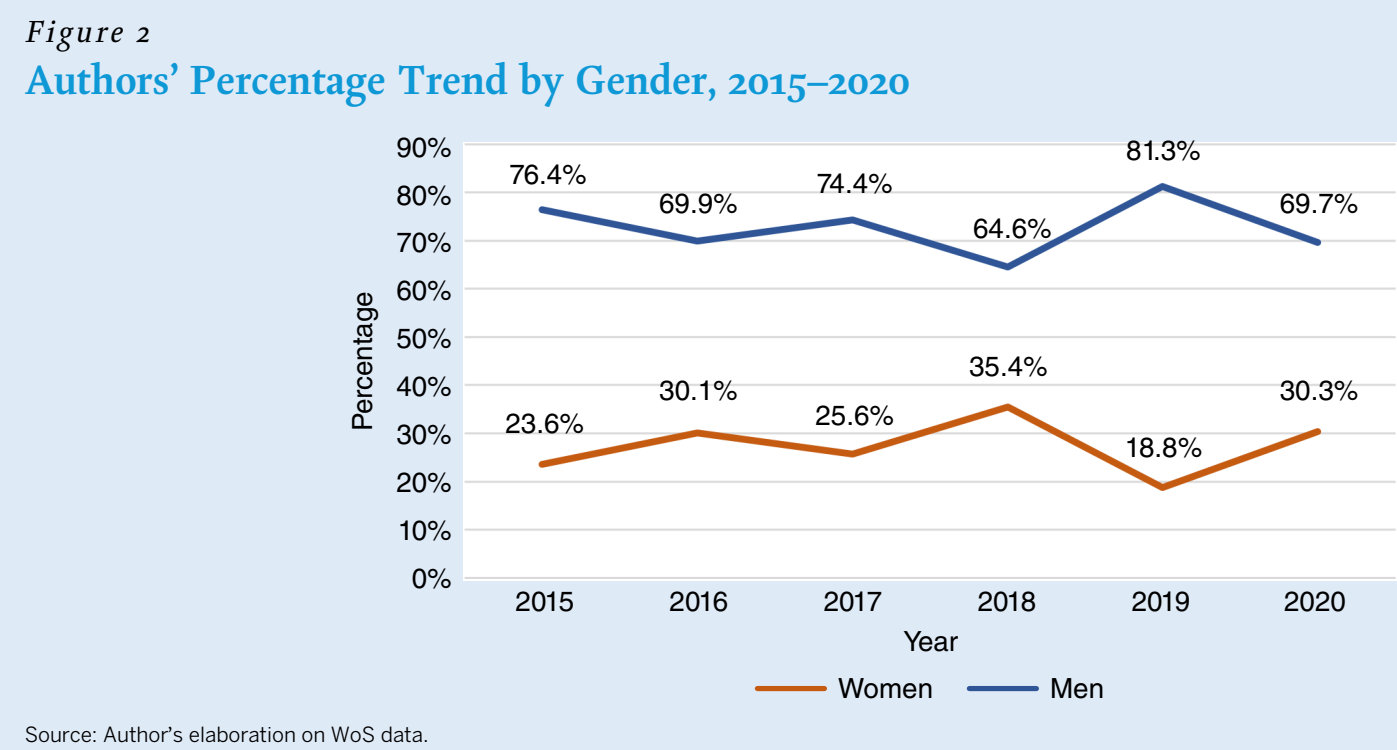

reduced from 2015 to 2018 before again increasing in 2019 and then decreasing in 2020. However, although the share of women has increased, it remained consistently lower than that of men.

This difference may depend on several factors, including the fact that women write and send fewer articles to the three journals and that there are fewer female researchers in political science than their male colleagues.

The first hypothesis cannot be verified because data are not available on submitted papers or on the peer-review process, which remains internal to each journal. However, it is possible publications written by two or more authors has been noted among international journals (Fisher et al. 1998; Teele and Thelen 2017). However, this trend is not registered among Italian publications in the discipline, in which articles written by single authors still represent the majority and show a steady trend in the period considered.

Of the total 414 articles analyzed, 253 were written by single male authors and 88 were written by single female authors. There were only 33 male collaborations and only eight female collaborations; there were 32 collaborations between men and women.

\section{The difference between women and men authors from 2015 to 2020 exhibited a fluctuating trend: the gender gap was progressively reduced from 2015 to 2018 before again increasing in 2019 and then decreasing in 2020.}

to compare publication data to data regarding the proportion of academic women in area 14 (figure 3).

As shown in figure 4, between 2015 and 2019, the average percentage of women holding a $\mathrm{PhD}$ in area 14 corresponds to slightly more than $50 \%$ of the total; the average percentage of female teaching and research staff corresponds to $43 \%$. Notwithstanding, the percentage of female-authored publications varied from $24 \%$ to $31.3 \%$. Assuming that men and women tend to submit the same number of articles, on average, the differences in those published do not seem to depend on a substantial difference in the number of men and women in the academic profession in the field of political science. Figure A1 in the online appendix reports the correlation between the percentages of female-authored publications and female teaching and research staff from 2015 to 2019.

Figure 4 shows the trend of publications according to authors' numbers and gender (figure $\mathrm{A} 2$ in the online appendix reports the percentages of authorship type by authors' gender). The data highlight some of the differences between Italian and international political science. In recent decades, an increase in
In reviewing the data more closely, however, it appears that differences in collaboration patterns also depend on the methodology used. Whereas RISP-which publishes a substantial share of quantitative articles-reports $56 \%$ of multi-authored articles in the period considered, $F S$ and $P \mathcal{E} S$-which are qualitative and theoretically oriented-report $1 \%$ and $4 \%$ of multi-authored articles, respectively. This confirms the findings in previous literature that highlights how collaboration is more common in quantitative rather than qualitative studies.

As discussed previously, in the context of Italian political science, there continue to be substantial gender differences in scientific publication, and these differences also are reflected in the career progression of researchers. Figure 5 shows average percentages by gender, for 2015-2018, in the different phases of an academic career: doctorate; research grant; RTDa; RTDb; ASN; and PA-PO professorship.

Data clearly show the precise moment at which the phenomenon known as the "leaky pipeline" occurs (Van den Brink and Benschop 2012). In fact, there is substantial equality between women and men among $\mathrm{PhD}$ holders; indeed, the female 


\section{Figure 3}

\section{Female Authors' Percentage and Area 14 Female Teaching Staff and Female PhDs Average} Percentages, 2015-2019

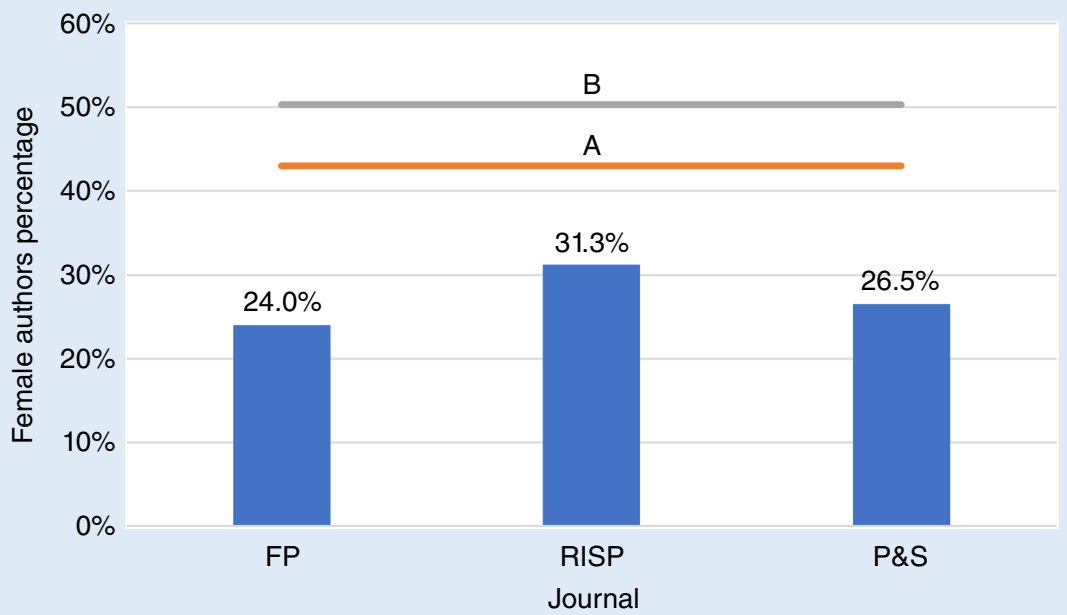

Source: Author's elaboration on WoS data and MIUR data.

Note: Line A represents the female teaching/research staff average percentage; line B represents the average percentage of female PhDs.

Figure 4

\section{Authorship Publication Trends by Type and Gender, 2015-2020}

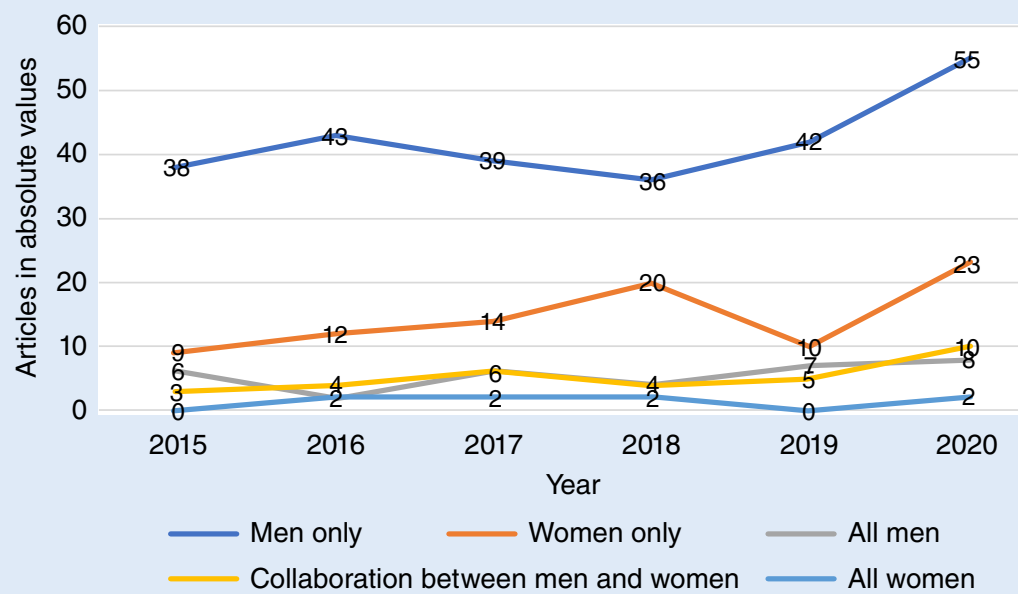

Source: Author's elaboration on WoS data.

component is an 0.8 percentage point higher than the male component. The female component then increases among research fellows, exceeding the male component by 9.4 percentage points. Among RTDas, the female component falls slightly less than the male component (i.e., $48.8 \%$ and $53.2 \%$, respectively) but remains in a condition of substantial equality. RTDbs, conversely, register a collapse of the female component, which represents $30.6 \%$ versus $69.4 \%$ of the male component, marking the point where the so-called leaky pipeline occurs. This loss is not reabsorbed in the final stages of the academic career that continue with the ASN, transitioning from researcher to associate professor and then to full professor, where the female component represents $40 \%$ of total PA professors but only $27 \%$ of PO professors.

\section{CONCLUSIONS}

The literature identifies different dimensions of the academic profession that register gender gaps. The hard-science sectors show greater gender gaps; however, even the social sciences data show considerable differences. The gender gap related to publications in scientific journals is particularly relevant because publishing scholars' research is essential to their academic career advancement. By analyzing publications of the three major Italian political science journals from 2015 to 2020 , this article focuses on gender differences related to scientific publications.

Comparing the WoS data with the data relating to journal editors and women in the various phases of their academic career revealed marked gender differences in the field of Italian political 
Figure 5

Average Percentage Breakdown in Different Phases of the Academic Career by Gender, 20152018

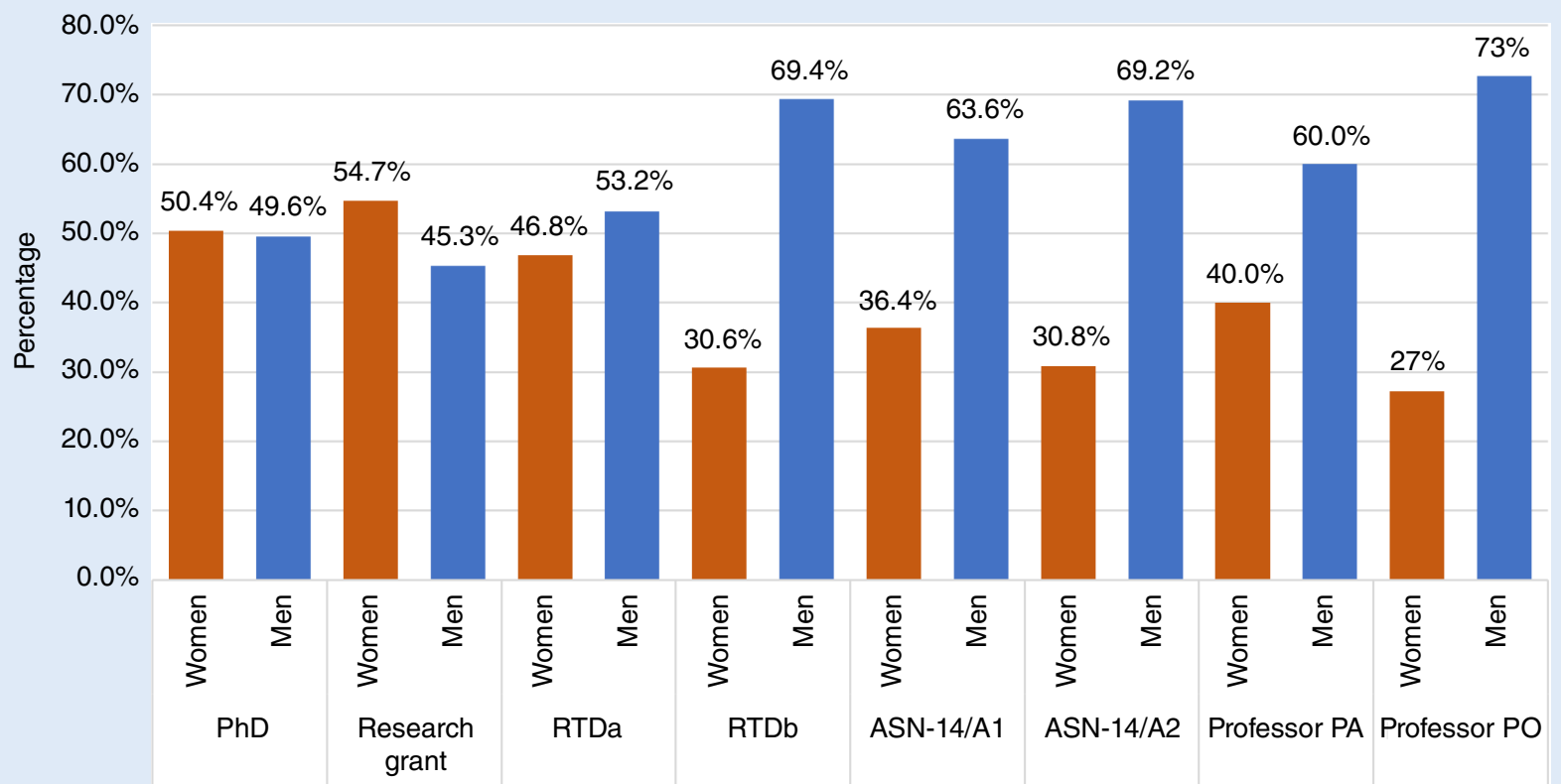

Source: Author's elaboration on WoS, ANVUR, and MIUR data.

science. First, the analysis shows that during the period of study, the proportion of scientific articles published by female authors was always lower than that of male authors. This trend has fluctuated, alternating periods in which the gender gap tended to both decrease and increase. affects career progression. Of course, because this analysis is purely descriptive, the need remains to deepen the knowledge about this issue and to understand the reasons for the gender gap in scientific publications, how it is related to career progression, and the differences between the national and international con-

\section{Confirming results of research conducted at the international level, this article highlights the gender gap in Italian political science publications and how this gap affects career progression.}

Second, the analysis highlights the incorrect hypothesis that posits that the lower female-authored production of scientific articles depends on fewer females in the discipline. Despite a progressive increase in the female component in all phases of the academic career, female-authored publications remain substantially lower than male-authored publications.

Third, the results show poor collaboration between men and women, which represents a negligible share of the publications examined. The analysis also found a strong correlation between female journal editors and the percentage of female-authored articles published.

Fourth, the analysis highlights how all of these gender differences in publications are reflected in the career progression of Italian political scientists; that RTDb is the precise moment in an academic career when the leaky-pipeline phenomenon occurs; and that the loss is not reabsorbed in subsequent career phases.

Confirming results of research conducted at the international level, this article highlights the gender gap in Italian scientific publications in the field of political science and how this gap texts. This is important not only for the purpose of knowledge but also to allow policy makers to adopt tailored measures that can assess the problem. In this sense, the strategy of focusing on national rather than international journals may achieve these objectives.

Indeed, the differences do not seem to depend on the presence of women in Italian political science, but it is possible that female researchers tend to submit fewer articles than their male counterparts or that the gender gap is influenced by the collaboration pattern as well as by the low percentage of female senior researchers. Due to the lack of data, this hypothesis remains under-investigated.

To test this hypothesis and to shed further light on the phenomenon, it is necessary to implement a data-collection policy that answers this question. Several recent studies investigating scholars' submissions have been done through individual authors' collaborations with publishers, but they are sparse and unsystematic. Increasing and fostering the collaboration with publishers, therefore, is essential to attain this goal. Publishers should begin 
to implement in-house policies of collection, systematization, and publication of data related to the submission and the peer-review processes. To facilitate the study of the gender gap in scientific publication, it is necessary to create and implement a data-collection standard shared and used by as many publishers as possible and, moreover, to create ad-hoc databases that can be accessed by researchers.

\section{ACKNOWLEDGMENTS}

I thank my colleagues at the Institute for Research on Population and Social Policies of the Italian National Research Council for their valuable feedback on a previous version of this article. In particular, I thank Sveva Avveduto and Maria Cristina Antonucci for their insightful comments and suggestions that helped me to notably improve the manuscript. I also thank the two anonymous reviewers for their pertinent and useful comments that helped me to further improve this version. Finally, I thank Constance Burt for her impressive copyediting of the final version of the article.

\section{DATA AVAILABILITY STATEMENT}

Research documentation and data that support the findings of this study are openly available at the PS: Political Science $\mathcal{E}$ Politics Harvard Dataverse at https://doi.org/10.7910/DVN/YEFLJZ.

\section{SUPPLEMENTARY MATERIALS}

To view supplementary material for this article, please visit http:// dx.doi.org/10.1017/S1049096521001037. .

\section{NOTES}

1. See http://web.apsanet.org/cswp/data.

2. Fixed-term researcher referred to in Article 24, paragraph 3, letter (a) of Law 240 of 2010. Contracts have a duration of three years, renewable for an additional two years.

3. Fixed-term researcher referred to in Article 24, paragraph 3 , letter (b) of Law 240 of 2010. Three-year nonrenewable contracts at the end of which it is possible to directly access the role of PA professor, if the individual has ASN.

4. See http://dati.ustat.miur.it/organization/ace58834-5aob-4of6-9boe-ed6c34ea8deo? tags $=$ Universit $\% \mathrm{C}_{3} \%$ Ao\&tags $=$ Personale .

5. See https://abilitazione.miur.it/public/pubblicarisultati_2016.php.

\section{REFERENCES}

Aguinis, Herman, Young Hun Ji, and Harry Joo. 2018. "Gender Productivity Gap among Star Performers in STEM and Other Scientific Fields." Journal of Applied Psychology 103 (12): 1283-306. https://doi.org/10.1037/aplooo0331.

Alter, Karen Jane, Jean Clipperton, Emily Schraudenbach, and Laura Rozier. 2020. "Gender and Status in American Political Science: Who Determines Whether a Scholar Is Noteworthy?" Perspectives on Politics 18 (4): 1-20. https://doi.org/

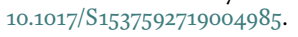

Avveduto, Sveva (ed.). 2019. Ricerca: Femminile, Plurale. Rome: CNR Edizioni. https:// doi.org/10.1460o/9788888080369o.

Breuning, Marijke, Benjamin Isaak Gross, Ayal Feinberg, Melissa Martinez, Ramesh Sharma, and John Ishiyama. 2018. "Clearing the Pipeline? Gender and the Review Process at the American Political Science Review." PS: Political Science \& Politics 51 (3): 629-34. https://doi.org/10.1017/S1049096518000069.

Breuning, Marijke, and Kathryn Sanders. 2007. "Gender and Journal Authorship in Eight Prestigious Political Science Journals." PS: Political Science \& Politics 40 (2): 347-51. https://doi.org/10.1017/S1049096507070564.

Brown, Nadia E., and David Samuels. 2018. "Beyond the Gender Citation Gap: Comments on Dion, Sumner, and Mitchell." Political Analysis 26 (3): 328-30. https://doi.org/10.1017/pan.2018.14.
Brown, Nadia E., Yusaku Horiuchi, Mala Htun, and David Samuels. 2020. "Gender Gaps in Perceptions of Political Science Journals." PS: Political Science \& Politics 53 (1): 114-21. https://doi.org/10.1017/S1049096519001227.

Case, Clarence Marsh. 1927. "Scholarship in Sociology." Sociology and Social Research 12:232-340.

Ceci, Stephen J., and Wendy M. Williams. 2010. "Sex Differences in Math-Intensive Fields." Current Directions in Psychological Science 19 (5): 275-79. https:// doi.org/10.1177/0963721410383241.

Ceci, Stephen J., and Wendy M. Williams. 2011. "Understanding Current Causes of Women's Underrepresentation in Science." Proceedings of the National Academy of Sciences 108 (8): 3157-62. https://doi.org/10.1073/pnas.1014871108.

Cellini, Marco. 2021. "Replication Data for: 'Gender Gap in Political Science: An Analysis of the Scientific Publications and Career Paths of Italian Political Scientists." Harvard Dataverse. https://doi.org/10.7910/DVN/YEFLJZ.

Dion, Michelle L., Jane Lawrence Sumner, and Sara McLaughlin Mitchell. 2018. "Gendered Citation Patterns across Political Science and Social Science Methodology Fields." Political Analysis 26 (3): 312-27. https://doi.org/10.1017/ pan.2018.12.

Djupe, Paul A., Amy Erica Smith, and Anand Edward Sokhey. 2019. "Explaining Gender in the Journals: How Submission Practices Affect Publication Patterns in Political Science." PS: Political Science \& Politics 52 (1): 71-77. https://doi.org/ 10.1017/S104909651800104X.

Egghe, Leo, and Ronald Rousseau. 199o. Introduction to Informetrics: Quantitative Methods in Library, Documentation, and Information Science. Amsterdam: Elsevier Science Publishers.

Fisher, Bonnie S., Craig T. Cobane, Thomas M. Vander Ven, and Francis T. Cullen. 1998. "How Many Authors Does It Take to Publish an Article? Trends and Patterns in Political Science." Political Science \& Politics 31 (4): 847-56. https:// doi.org/10.2307/420730.

Gauffriau, Marianne. 2017. "A Categorization of Arguments for Counting Methods for Publication and Citation Indicators." Journal of Informetrics 11 (3): 672-84. https://doi.org/10.1016/j.joi.2017.05.009.

Korytkowski, Przemyslaw, and Emanuel Kulczycki. 2019. "Publication Counting Methods for a National Research Evaluation Exercise." Journal of Informetrics 13 (3): 804-16. https://doi.org/10.1016/j.joi.2019.07.001.

Larsen, Peder. 2008. "The State of the Art in Publication Counting." Scientometrics 77 (2): 235-51. https://doi.org/10.1007/s11192-007-1991-6.

MacNell, Lillian, Adam Driscoll, and Andrea N. Hunt. 2015. "What's in a Name: Exposing Gender Bias in Student Ratings of Teaching." Innovative Higher Education 40 (4): 291-303.

Nedal, Dani K., and Daniel H. Nexon. 2018. "Gender in the International Studies Quarterly Review Process." PS: Political Science \& Politics 51 (4): 859-65. https:// doi.org/10.1017/S1049096518000628.

Samuels, David. 2018. "Gender and Editorial Outcomes at Comparative Political Studies." PS: Political Science \& Politics 51 (4): 854-58. https://doi.org/10.1017/ S1049096518000616.

Stegmaier, Mary, Barbara Palmer, and Laura Van Assendelft. 2011. "Getting on the Board: The Presence of Women in Political Science Journal Editorial Positions." Political Science \& Politics 44 (4): 799-804. https://doi.org/10.1017/ S1049096511001284.

Teele, Dawn Langan, and Kathleen Thelen. 2017. "Gender in the Journals: Publication Patterns in Political Science." Political Science \& Politics 5o (2): 433-47. https://doi.org/10.1017/S1049096516002985.

Van den Brink, Marieke, and Yvonne Benschop. 2012. "Slaying the SevenHeaded Dragon: The Quest for Gender Change in Academia." Gender, Work \& Organization 19 (1): 71-92. https://doi.org/10.1111/j.14680432.2011.00566.x.

Van Hooydonk, Guido. 1997. "Fractional Counting of Multi-Authored Publications Consequences for the Impact of Authors." Journal of the American Society for Information Science 48 (10): 944-45. https://doi.org/10.1002/(SICI)1097-4571 (199710) 48:10<944::AID-ASI8>3.0.CO;2-1.

Wang, Ming-Te, and Jessica L. Degol. 2017. "Gender Gap in Science, Technology, Engineering, and Mathematics (STEM): Current Knowledge, Implications for Practice, Policy, and Future Directions." Educational Psychology Review 29 (1): 11940. https://doi.org/10.1007/s10648-015-9355-x.

Young, Cheryl D. 1995. "An Assessment of Articles Published by Women in 15 Top Political Science Journals." Political Science \& Politics 28 (3): 525-33. https:// doi.org/10.2307/420325.

Wennerås, Christine, and Agnes Wold. 1997. "Sexism and Nepotism in Peer Review." Nature 387 (6631): 341-43. 